\title{
Effect of Reflexology Therapy On Decreased Intensity of Menstrual Pain
}

\author{
Nur Afni ${ }^{1}$, Tenriwati ${ }^{2 *}$, Haerati ${ }^{3}$ \\ ${ }^{1}$ Nursing Student, Stikes Panrita Husada Bulukumba, Indonesia \\ ${ }^{2,3}$ Department of Nursing Stikes Panrita Husada Bulukumba, Indonesia
}

Corresponding author: Tenriwati

Email: tenriwatisalala@gmail.com

\begin{abstract}
ABSTRACK
Pharmacological treatment of menstrual pain relief and non-pharmacological treatment such as reflexology, reflexology massage can be done on the feet and hands so that these points provide a spontaneous relaxation stimulation when massaged so that pain is not felt. Purpose The purpose of this study was to determine the effect of giving reflexology therapy on reducing the intensity of menstrual pain in undergraduate nursing study program students at Panrita Husada College of Health Sciences, Bulukumba. Methods This study used a pre-experimental design with a one group pretestposttest design approach. The sample of this study was 41 respondents who were taken using nonprobability sampling method with consecutive sampling technique. The experimental group received reflexology therapy once with a duration of 20 minutes. Analysis of the data in this study using the Wilcoxon test statistic. The results of the analysis used the Wilcoxon test statistical test with a level of confidence $(\alpha=0.05)$. Based on the results of this test, the value of $\rho=0,000$ was obtained, thus $\rho<\alpha$ $(0,000<0.05)$, so there was an effect of giving reflexology therapy on reducing the intensity of menstrual pain in undergraduate nursing study program students at Stikes Panrita Husada Bulukumba. The conclusion of this study is a Researchers suggest that the results of this study can provide information for people in the surrounding environment, families and young women about how to deal with menstrual pain without consuming pharmacological drugs but in a non-pharmacological way, namely by using reflexology techniques.
\end{abstract}

\section{Keywords: Reflexology, Menstrual Pain (Dysminorrhea)}




\section{PENDAHULUAN}

Manusia merupakan makhluk yang tumbuh dan berkembang, salah satu di antaranya yaitu memasuki masa remaja, masa remaja pada wanita di tandai dengan berbagai pertumbuhan dan perkembagan baik secara fisik, emosi, kognitif dan sosial. Pertumbuhan dan perkembagan pada wanita yang paling menonjol yaitu terjandinya menstruasi, pada saat wanita fase menstruasi banyak penyakit yang dapat timbul salah satunya nyeri haid atau dismenore, dismenore terbagi menjadi dua yaitu disminore primer dan dismenore sekunder (Mariza Elvira, 2018). Menurut World Health Organization (WHO) angka kejadian dismenore sebesar $81 \%$ penduduk yang mengalami disminore (Pratiwi et al., 2019). Dengan gejala disminore berupa rasa sakit dan kram perut bagian bawah yang di alami wanita beberapa jam sebelum menstruasi dan berlangsung selama 48 -72 jam (Berger, 2019). Dismenore terjadi 3-5 tahun setelah menarche seiring dengan berlangsungnya siklus ovulatorik dan mencapai klimaks di usia 15 -25 tahun (Irianti, 2018).

Berdasarkan data angka kejadian dismenore di Amerika Serikat sekitar $49 \%$ mengalami disminore ringan, $37 \%$ disminore sedang dan $12 \%$ mengalami dismenore berat. Sementara di Indonesia di perkirakan $55 \%$ wanita mengalami dismenore di usia produktif (Ninna Novriyana, 2018). Sehingga dismenore memiliki dampak terhadap fisik, psikologis, social ,ekonomi dan aktivitas mahasiswi. Berdasarkan data jumlah mahasiswi yang tidak mengikuti pelajaran dikelas pada saat dismenore sebanyak 41 (68\%), tidak mengikuti kegiatan kampus 27 (45\%), hanya tiduran 29 (48\%), sulit berjalan sebanyak 39 (65\%), nilainya menjadi rendah sebesar $(6,5 \%)$, konsentrasi belajar menurun $(87,1 \%)$ dan $(80,6 \%)$ tidak mengikuti mata kuliah (Iswari, 2014). Dari penelitian yang di lakukan Fakultas kedokteran Universitas Hasanudin (UNHAS) dari 935 (93,8\%) kasus sebanyak 53,9\% mengalami dismenore di usia 13-15 tahun yang mengakibatkan intoleran aktifitas (Trianingsih, 2016).

Dari hasil penelitian yang dilakukan oleh (Sepriana, 2017), perasaan tidak nyaman akibat dismenore akan mempengaruhi fungsi mental dan fisik individu sehingga harus di tagani dengan terapi farmakologis dan non farmakologis. Penaganan secara farmakologi pemberian pereda nyeri haid dan penaganan secara non farmakologis seperti pijat refleksi, pijat reflesksi dapat di lakukan pada kaki dan tanggan sehingga titik tersebut memberikan rangsagan rileks secara spontan saat di pijat. Berdasarkan hasil wawancara dengan beberapa mahasiswi di Sekolah Tinggi Ilmu Kesehatan Panrita Husada Bulukumba beberapa mahasiswi mengatakan ketika mengalami dismenore terdapat satu orang yang di bawa ke ruang IGD 
karena nyeri berat yang dirasakan, terdapat pula mahasiswi yang tidak dapat beraktifitas sama sekali hanya berbaring, selebihnya mereka hanya memijat perut dan minum obat anti nyeri, namun ketika menggonsumsi obat-obatan tersebut haidnya tidak lancar sehingga hal tersebut dapat menimbulkan lagi masalah, berdasarkan hasil uji coba dengan salah satu mahasiswi yang di berikan terapi pijat refleksi pada saat menggalami disminore dan pijat tersebut berpengaruh terhadap penurunan intensitas nyeri haid maka dari itu saya tertarik untuk membantu mereka yang mengalami dismenore dengan pijat refleksi tanpa mengonsumsi obatobatan farmakologi selain itu melihat bayaknya angka kejadian disminore yang mengganggu aktifitas penderitanya sehingga saya tertarik untuk melakukan penelitian tentang "Apakah ada pengaruh Terapi Pijat Refksi Terhadap Penurunan Nyeri Haid Pada Mahasiswi Di Sekolah Tinggi Ilmu Kesehatan Panrita Husada Bulukumba”.

\section{BAHAN DAN METODE}

\section{Desain Penelitian}

Desain dalam penelitian ini bersifat kuantitatif dengan menggunakan desain pre eksperimen dengan pendekatan one grup pretest -posttest design.Untuk mengetahui adanya pengaruh pemberian terapi pijat refleksi terhadap penurunan intensitas nyeri haid pada mahasiswi prodi S1 keperawatan di stikes panrita husada bulukumba.

\section{Populasi Dan Sampel}

Populsi merupakan wilayah generalisasi yang terdiri dari obyek/subjek yang mempunyai kualitas dan karakteristik tertentu yang ditetapkan oleh peneliti untuk dipelajari dan kemudian ditarik kesimpulannya (Sugiyono 2017). Populasi pada penelitian ini adalah mahasiswi program studi S1 Keperawatan tingkat I, II, III, IV yang mengalami disminore di Stikes Panrita Husada Bulukumba yang berjumlah 80 responden. Jumlah sampel dalam penelitian ini sebanyak 41 responden pada mahasiswi prodi S1 Keperawatan di Stikes Panrita Husada Bulukumba.

\section{Tehnik sampling}

Tehnik sampling yaitu cara untuk menentukan jumlah sampel yang akan di gunakan oleh peneliti. Tehnik pengambilan sampel yang di gunakan dalam penelitian ini yaitu non probability sampling dengan tehnik consecutive sampling memilih semua sampel yang di temui dan memenuhi kriteria pemilihan sampai sampel yang di inginkan terpenuhi tehnik ini sering di gunakan untuk penelitian eksperimen (Dharma, 2017a). 


\section{HASIL}

Berdasarkan tabel 1 dapat di ketahui karakteristik responden berdasarkan pendidikan terakhir paling banyak berada pada SMA sebanyak 30 orang (73.2\%), kemudian SMK sebanyak 7 orang $(17.1 \%)$ dan paling sedikit berada pada MA sebanyak 4 orang $(9.8 \%)$. Berdasarkan usia paling banyak berada pada dewasa sebanyak 27 orang (65.9\%) kemudian remaja sebanyak 14 orang $(34.1 \%)$. Berdasarkan tingkat paling banyak berada pada tingkat empat sebanyak 12 orang (29.3\%), kemudian tingkat dua sebanyak 11 orang (26.8\%), tingkat satu sebanyak 10 orang (24.4\%) dan paling sedikit berada pada tingkat tiga sebanyak 8 orang (19.5\%). Berdasarkan hari mengalami disminore paling banyak berada pada haid hari kedua sebanyak $23(56.1 \%)$ responden dan paling rendah berada pada haid hari ke pertama sebanyak $18(43.9 \%)$ responden.

Tabel 1. Distribusi jumlah karakteristik responden berdasarkan pendidikan terakhir, usia, tingkat dan hari mengalami disminore

\begin{tabular}{lcc}
\hline \multicolumn{1}{c}{ Karakterisitik Responden } & Frekuensi ( F) & Persentase (\%) \\
\hline Pendidikan & 30 & 73,2 \\
SMA & 7 & 17,1 \\
SMK & 4 & 9,8 \\
MA & & \\
Usia & 14 & 34,1 \\
Remaja & 27 & 65,9 \\
Dewasa & & \\
Tingkat & 10 & 24,4 \\
Tingkat 1 & 11 & 26,8 \\
Tingkat 2 & 8 & 19,5 \\
Tingkat 3 & 12 & 29,3 \\
Tingkat 4 & & \\
Disminorea & 18 & 43,9 \\
Haid Hari pertama & 23 & 56,1 \\
Haid Hari Kedua & Total & $\mathbf{1 0 0 , 1}$ \\
\hline
\end{tabular}

Berdasarkan hasil uji wilcoxon pada tabel 2 dari 41 orang responden $100.0 \%$ di dapatkan data nyeri ringan 2 orang responden (4.9\%), nyeri sedang 22 orang responden $(53.7 \%)$ dan nyeri berat 17 orang responden (41.5\%). 
Tabel .2 Distribusi jumlah responden berdasarkan tingkat nyeri haid pre test pijat refleksi

\begin{tabular}{lcc}
\hline \multicolumn{1}{c}{ Tingkat Nyeri } & Frekuensi (F) & Persentase (\%) \\
\hline Nyeri Ringan & 2 & 49,1 \\
Ntyeri Sedang & 22 & 53,7 \\
Nyeri Berat & 17 & 41,5 \\
\hline \multicolumn{1}{c}{ Total } & $\mathbf{4 1}$ & $\mathbf{1 0 0 , 0}$ \\
\hline
\end{tabular}

Berdasarkan hasil uji wilcoxon pada tabel 3 dari 41 orang responden $100.0 \%$ di dapatkan data yang mengalami nyeri ringan 25 orang responden (61.0\%), nyeri sedang 14 orang responden $(34.1 \%)$ dan nyeri berat 2 orang responden (4.9\%).

Tabel 3. Distribusi jumlah responden berdasarkan tingkat nyeri haid post test pijat refleksi

\begin{tabular}{lcc}
\hline \multicolumn{1}{c}{ Tingkat Nyeri } & Frekuensi (F) & Persentase (\%) \\
\hline Nyeri Ringan & 25 & 61,0 \\
Ntyeri Sedang & 14 & 34,1 \\
Nyeri Berat & 2 & 4,9 \\
\hline \multicolumn{1}{c}{ Total } & $\mathbf{4 1}$ & $\mathbf{1 0 0 , 0}$ \\
\hline
\end{tabular}

\section{Analisis Bivariat}

Dari Tabel 4 berdasarkan hasil Post Test Pijat Refleksi terjadi perubahan persentasi responden dari tingkat nyeri haid berat dari 17 orang responden (41.5\%) menjadi 2 orang responden (4.9\%), kemudian nyeri haid sedang dari 22 orang responden (53.7\%) menjadi 14 orang responden $(34.1 \%)$ dan kategori tingkat nyeri haid ringan dari 2 orang responden (4.9\%) menjadi 25 orang responden (61.0\%). Dari hasil analisis menggunakan uji statistic uji wilcoxon maka diperoleh nilai $\rho=0,00<\alpha=0,05$. Maka, berdasarkan hasil akhir tersebut dapat disimpulkan bahwa terdapat pengaruh pemberian terapi pijat refleksi terhadap penurunan intensitas nyeri haid pada mahasiswi prodi S1 Keperawatan di Stikes Panrita Husada Bulukumba

Tabel 4. Analisis perbedaan tingkat nyeri haid sebelum dan setelah di berikan terapi pijat refleksi

\begin{tabular}{lccccc}
\hline Kategori & \multicolumn{2}{c}{ Pretes Pijat Refleksi } & \multicolumn{2}{c}{ Post Test Pijat Refleksi } & P Value \\
\cline { 2 - 5 } & F & $\mathbf{\%}$ & F & \% & \\
\hline Nyeri Ringan & 2 & 4,9 & 25 & 61,0 & 0,00 \\
Nyeri Sedang & 22 & 53,7 & 14 & 34,1 & \\
Nyeri Berat & 17 & 41,5 & 2 & 4,9 & \\
\hline Total & $\mathbf{4 1}$ & $\mathbf{1 0 0}$ & $\mathbf{4 1}$ & $\mathbf{1 0 0}$ & \\
\hline
\end{tabular}

\section{PEMBAHASAN}

Disminore merupakan keluhan ginekologis yang sering di alami perempuan pada saat mestruasi, disminore di klasifikasikan menjadi dua bagian yaitu primer dan sekunder. 
Disminore atau nyeri haid primer yaitu nyeri yang di rasakan sejak haid pertama dan menghilang setelah stabilnya hormon tubuh, kemudian nyeri haid sekunder yaitu nyeri haid yang muncul ketika terdapat penyakit seperti polip/kista, infeksi rahim dan tumor di sekitar kandugan (Kusmiran, 2014).

Dismenore terjadi karena adanya jumlah prostaglandin F2 $\alpha$ yang belebih pada darah menstruasi yang merangsang hiperaktifitas uterus. Peningkatan prostaglandin menyebabkan kontraksi myometrum meningkat sehingga mengakibatkan aliran darah ke otot-otot rahim menjadi berkurang yang berakibat meningkatnya aktivitas rahim untuk memenuhi kebutuhannya akan aliran darah yang lancar terhadap otot dinding uterus mengalami iskemik dan disintegrasi endometrium sehingga menyebabkan rangsangan pada serabut saraf nyeri yang terdapat pada uterus meningkat, rangsangan berupa implus nyeri tersebut kemudian dihantarkan ke sel T sehingga rangsangan pada sel T menjadi kuat. Sel T kemudian bekerja sama dengan traktus spinothalamicus mengantarkan implus nyeri tersebut ke pusat nyeri yang di sebut dengan thalamus sehingga nyeri dapat di rasakan (Morgan dan Hamilton,2009) dalam jurnal (Zulian, 2017).

Dismenore jika tidak segera diatasi akan mempengaruhi fungsi mental dan fisik individu sehingga mendesak untuk segera di berikan tindakan (Elvira and Tulkhair, 2018). Dismenore dapat diatasi dengan terapi farmakologi dan non farmakologi. Terapi farmakologi antara lain, pemberian obat analgetik, terapi hormonal, obat nonsteroid prostaglandin dan dilatasi servikalis (Prawirohardjo, 2009). Kemudian terapi secara non farmakologi dapat dilakukan dengan olahraga ringan, kompres hangat, relaksasi, aroma terapi dan pijat. Pijat merupakan upaya manipulasi yang bertujuan untuk meningkatkan rileksasi otot, fleksibilitas, pengurangan nyeri dan perbaikan sirkulasi darah dan pengurangan nyeri, untuk mengurangi nyeri dismenore dapat dilakukan dengan cara terapi pijat refleksi.

Pijat refleksi bisa dilakukan dimana saja, akan tetapi untuk menghilangkan dismenore dapat dilakukan pijat refkleksi pada kaki. Pijat refleksi yang dilakukan pada kaki berfungsi untuk merangsang titik refleks dan membawa keseimbangan sistem tubuh agar dapat bekerja sama secara harmonis, titik-titik pada kaki akan memberikan rangsangan secara refleks atau spontan pada saat dipijat atau ditekan. Rangsangan tersebut akan mengalirkan semacam gelombang kejut atau listrik menuju otak. Gelombang tersebut diterima otak dan diproses dengan cepat, lalu diteruskan menuju saraf pada organ tubuh yang mengalami gangguan. 
Salah satu penyebab organ tubuh mengalami gangguan atau sakit adalah karena adanya penyumbatan aliran darah menuju organ tersebut.

Saat titik refleks dipijat atau ditekan, gelombang yang menghambat akan menghancurkan atau memecah penyumbatan tersebut sehingga aliran darah akan kembali lancar sehingga nyeri tidak di rasakan (Novriyana et al., 2018). Berdasarkan hasil penelitian yang di lakukan pada mahasiswi S1 Keperawatan di stikes panrita husada bulukumba dari 41 responden setelah di berikan terapi pijat refleksi di dapatkan hasil nyeri haid berat dari 17 orang responden $(41.5 \%)$ menjadi 2 orang responden (4.9\%), kemudian nyeri haid sedang dari 22 orang responden (53.7\%) menjadi 14 orang responden $(34.1 \%)$ dan kategori tingkat nyeri haid ringgan dari 2 orang responden (4.9\%) menjadi 25 orang responden $(61.0 \%)$.

Dari hasil penelitian tersebut dengan mengunakan uji wilcoxon dapat di lihat bahwa terdapat pengaruh terapi pijat refleksi terhadap penurunan intensitas nyeri haid pada mahasiswi S1 Keperawatan di stikes panrita husada bulukumba. Penelitian ini sesuai dengan penelitian (Paryono and Prihati, 2017) dengan judul pengaruh pijat refleksi terhadap penurunan nyeri haid pada wanita di panti yatim putri daerah klaten tahun 2016 Nyeri haid (desminore) dirasakan sebelum dilakukan pijat refleksi pada wanita di panti yatim putri daerah klaten tahun 2016 tergolong nyeri sedang. Nyeri haid (desminore) dirasakan setelah dilakukan pijat refleksi pada wanita di panti yatim putri daerah klaten tahun 2016 tergolong nyeri ringan. Kemudian hasil penelitian lain yang sesuai di lakukan (Novriyana et al., 2018) dengan judul Efektifitas pijat refleksi kaki pada area reproduksi Terhadap dismenore berdasarkan hasil penelitian yang dilakukan uji Wilcoxon didapatkan selisih median intensitas nyeri dismenore pretest dan posttest adalah 3,00. Hasil analisa data diperoleh $p$ value $(0,000)$ $<\alpha(0,05)$, maka dapat disimpulkan ada perbedaan median intensitas nyeri dismenore yang signifikan sebelum dan sesudah diberikan pijat refleksi kaki pada area reproduksi pada kelompok eksperimen.

Penelitian ini juga sejalan dengan penelitian (RENITYAS, 2017) dengan judul effectiveness of accupresure li4 to decreased pain dysmenorrhoe in adolescent teenage, dari hasil penelitian ini didapatkan data bahwa terdapat efektifitas titik accupresure li4 terhadap penurunan nyeri dismenore pada remaja putri. Akupresur yaitu memberikan Pijatan yang berfungsi untuk menstimulasi titik-titik tertentu melalui jaringan syaraf yang akan memberi stimulus pada Sistem endokrin untuk melepaskan endorfin sesuai kebutuhan tubuh yang berfungsi untuk menurunkan rasa nyeri saat menstruasi. 
Disminore di klasifikasikan menjadi dua yaitu disminore primer dan disminore sekunder (Kusmiran, 2014). Pada penelitian ini terdapat 2 orang responden sebelum di berikan perlakuan mengalami nyeri berat dan setelah di berikan perlakuan tetap mengalami nyeri berat hal ini bisa dipengaruhi oleh nyeri sekunder yaitu nyeri haid yang muncul ketika terdapat penyakit seperti polip/kista, infeksi rahim dan tumor di sekitar kandugan (Kusmiran, 2014).

Adapun asumsi peneliti terkait hasil penelitian ini adalah mahasiswi yang mengalami nyeri haid atau dismenore mengakibatkan aktifitas tergangu dan ketidak nyamanan. Salah satu cara penaganan non farmakologi yang dapat di lakukan pada saat mengalami dismenore yaitu pijat refleksi. Sentuhan atau pijatan yang di lakukan pada titik reproduksi, akan di tanggapi oleh reseptor kemudian langsung di ubah menjadi implus syaraf atau perjalanan rangsangan, terjadinya perubahan dari keadaan polarisasi menjadi depolarisasi, kemudian di bawah oleh neurotrasimister menuju sel p, prostaglandin dan serotonin, merangsang neuromodilator pada endorphin sehingga nyeri di blok dan nyeri tidak di rasakan.

\section{KESIMPULAN DAN SARAN}

Berdasarkan hasil uji menggunakan uji wilcoxon di dapatkan nilai $\rho=0,00$ bahwa terdapat pengaruh pijat refleksi terhadap penurunan intensitas nyeri haid pada mahasiswi program studi S1 keperawatan di stikes panrita husada bulukumba. Diharapkan dari hasil penelitian ini dapat membantu memahami bagaimana pijat refleksi dapat menurunkan intensitas nyeri haid. Agar hasil penelitian ini dapat memberikan informasi bagi masyarakat yang ada di lingkungan sekitar, keluarga serta remaja putri tentang bagaimana cara mengatasi nyeri haid tanpa mengonsumsi obat-obat farmakologi melainkan dengan cara non farmakologi yaitu dengan tehnik pijat refleksi.

\section{DAFTAR PUSTAKA}

Ariyani, H. D. Y. (Ed.) 2015. Ilmu Pijat Pengobatan Refleksi Relaksasi, Jakarta: Direktorat Pembinaan Kursus Dan Pelatihan.

Berger 2019. Personal Perception And Body Awareness Of Dysmenorrhea And The Effects Of Rhythmical Massage Therapy And Heart Rate Variability Biofeedback-A Qualitative Study In The Context Of A Randomized Controlled Trail. Jurnal Complementary Therapies In Medicine.

Dharma, K. K. (Ed.) 2017. Metodologi Penelitian Keperawatan Pedoman Melaksanakan Dan Menerapkan Hasil Penelitian, Jakarta: Trans Info Media. 
Dwienda, Megasari \& Lusiana 2015. Efektivitas Pijat Dalam Mengurangi Nyeri Pada Kala I Persalinan. Jurnal Kesehatan Komunitas.

Eka Yuli Handayani, A. S. 2018. Pencegahan Nyeri Haid Melalui Pemanfaatan Terapi NonFarmakologi Pada Remaja Putri Sman I Tambusai. Journal Of Midwifery Science, Vol 2.

Elvira, M. \& Tulkhair, A. 2018. Pengaruh Pijat Endorphine Terhadap Skala Nyeri Pada Siswi Sma Yang Mengalami Disminore. Jurnal Iptek Terapan.

Ira Trionggo, A. G. (Ed.) 2013. Panduan Sehat Sembuhkan Penyakit Dengan Pijat Dan Herbal, Yogyakarta: Indoliterasi.

Irianti, B. 2018. Faktor- Faktor Yang Mempengaruhi Kejadian Dismenore Pada Remaja. Menara Ilmu, Xii.

Iswari, D. P. 2014. Hubungan Dismenore Dengan Aktivitas Belajar Mahasiswi Psik Fk Unud Tahun 2014.

Kusmiran, E. (Ed.) 2014. Kesehatan Reproduksi Remaja Dan Wanita, Jakarta: Salemba Medika.

Laili, N. 2012. Perbedaan Tingkat Nyeri Haid (Dismenore) Sebelum Dan Sesudah Senam Dismenore Pada Remaja Putri Di Sman 2 Jember.

Mariza Elvira, A. T. 2018. Pengaruh Pijat Endorphine Terhadap Skala Nyeri Pada Siswi Sma Yang Mengalami Disminore. Iptek Terapan, 12.

Novriyana, N., Utami, S. \& Dewi, Y. I. 2018. Efektifitas Pijat Refleksi Kaki Pada Area Reproduksi Terhadap Dismenore. Jom Fkp Vol 5.

Nursalam (Ed.) 2016. Metodologi Penelitian Ilmu Keperawatan Pendekatan Praktis Jakarta: Salemba Medika.

Parjan, A. (Ed.) 2016. Titik Ajaib Tumpas Penyakit, Yogyakarta: Genius Publisher.

Paryono \& Prihati, D. R. 2017. Pengaruh Pijat Refleksi Terhadap Penurunan Nyeri Haid Pada Wanita Di Panti Yatim Putri Daerah Klaten Tahun 2016. Jurnal Terpadu Ilmu Kesehatan, Volume 6.

Pratiwi, J. R., Parellangi, N. A., Lingga, E. R. B. \& Hariyani, F. 2019. Efikasi Diri Dan Kecemasan Terhadap Kejadian Dismenore Siswi Smp Negeri 5 Samarinda. Journal Mahakam Midwifery Vol 3.

Renityas, N. N. 2017. Effectiveness Of Accupresure Li4 To Decreased Pain Dysmenorrhoe In Adolescent Teenage. Vol 1. 
Sepriana, E. S. C. 2017. Pengaruh Pemberian Massage Petrissage Terhadap Penurunan Dismenorea Pada Siswi Man 2 Sumbawa Besar. 3.

Setiadi (Ed.) 2013. Konsep Dan Praktik Penulisan Riset Keperawatan Yogyakarta: Graha Ilmu.

Sugiyono (Ed.) 2017. Metode Penelitian Kuantitatif,Kualitatif Dan R\&D, Bandung: Alfabeta.

Sulasmono, G. (Ed.) 2016. Saraf Kunci Tumpas Ragam Penyakit Panduan Pijat Refleksi, Yogyakarta: Trans Idea Publishing.

Sumantri, A. (Ed.) 2011. Metodologi Penelitian Kesehatan Jakarta: Kencana Prenada Media Group.

Syamsuddin, Muriyati, Asdinar \& Sumarni (Eds.) 2015. Pedoman Praktis Metode Penelitian Internal, Ponorogo: $\mathrm{Cv}$ Wade Group.

Taufan Nugroho, B. I. U. (Ed.) 2017. Masalah Kesehatan Reproduksi Wanita, Yogyakarta: Nuha Medika.

Trianingsih, N. W. 2016. Efektifitas Perbedaan Terapi Akupresur Dan Muscle Stretching Exercise Terhadap Intensitas Nyeri Pada Remaja Putri Dengan Dismenore. Jurnal Kebidanan Vol 5.

Wulandari, D. A. D. A. (Ed.) 2011. Cara Jitu Mengatasi Nyeri Haid, Yogyakarta: Andi.

Zulfa, R., Wardini, L. P. S. \& Dyah, S. P. (Eds.) 2018. Terapi Komplementer, Mojokerto: Stikes Majapahit Mojokerto.

Zulian, A. 2017. Akupresur Efektif Mengatasi Dismenorea. Jppni, Vol 02. 